Hospital Practice

\title{
The use of lumbar puncture in a district general hospital
}

\author{
David B.G. Oliveira
}

Ealing Hospital, Uxbridge Road, Southall, Middlesex, UK.

\begin{abstract}
Summary: A survey of lumbar punctures performed in adults in a district general hospital over a two year period was carried out. As well as being used for conventional, specific indications, lumbar puncture was often employed as a screening investigation in undiagnosed neurological illness. Although this was not inappropriate in patients with meningeal symptoms and signs, or patients with disordered consciousness, lumbar puncture was also used in patients with focal neurological signs. Although the dangers of lumbar puncture in these latter patients, and the fact that it is unlikely to yield information unobtainable by other investigations have been stated by many authorities, almost $20 \%$ of patients fell into this group. This suggests that these points require further emphasis.
\end{abstract}

\section{Introduction}

The lumbar puncture has been used in clinical medicine for almost one hundred years (Craigmile \& Welch, 1973). Despite the accumulation of a considerable body of literature on numerous aspects, there is little information on the use of lumbar puncture in general medical practice today and with what results. I therefore performed a retrospective survey of the lumbar punctures performed in adults in a district general hospital over a two year period.

\section{Patients and methods}

Ealing Hospital is a district general hospital serving a population of approximately 200,000 which includes a large Asian community. There is no on site computerized tomographic (CT) scanning, but this is usually available at a nearby centre within a few hours. The pathology department maintains a log book of all submitted cerebro-spinal fluid samples from which a list of all patients on whom lumbar puncture was performed in the years 1981 and 1982 was obtained. Cases from the paediatric wards were excluded. The available notes of these adult patients were reviewed.

Correspondence and present address: D.B.G. Oliveira M.A., M.R.C.P., Department of Zoology, University College London, Gower Street, London WC1E 6BT, UK.

Accepted: 6 August 1985.

\section{Results}

During the years 1981-2, 39 lumbar punctures were performed during myelography and are not considered further. The notes of four patients, all of whom had normal lumbar punctures, could not be traced. The remaining 113 patients, who had a total of 124 lumbar punctures during this time, form the basis of this report. Almost all medical admissions to Ealing Hospital are via the Accident and Emergency Department, and during the years 1981-2 there were a total of 5391 such admissions, giving a crude rate of one patient undergoing lumbar puncture(s) per 46 admissions (including the four patients whose notes could not be traced).

Of the 113 patients, 22 had lumbar puncture performed for a clearly defined indication (Table I). In the remaining 91 patients it was often not possible to discern a clear indication for lumbar puncture. These patients could be divided into four groups on clinical grounds with only minimal overlap. Group 1 (34 patients) presented with meningeal symptoms or signs (headache, nausea, vomiting, photophobia, neck stiffness, positive Kernig's sign). Group 2 (22 patients) and Group 3 (14 patients) both presented with disordered consciousness, the former acutely, the latter subacutely. In addition two patients in Group 2 had mild neck stiffness, and one a fixed pupil. All the patients in Group 4 (21 patients) had focal neurological signs. In addition, six had variable degrees of neck stiffness.

After division into these groups, the contribution of lumbar puncture to diagnosis and the final diagnosis (Table II) were determined. The presence of pyrexia or 
Table I Patients undergoing lumbar puncture for specific indications.

\begin{tabular}{|c|c|c|}
\hline Clinical context & No. & Final diagnosis/outcome \\
\hline $\begin{array}{l}\text { ? Neurosyphilis } \\
\text { Known lymphoma/ } \\
\text { leukaemia,? meningeal } \\
\text { involvement }\end{array}$ & $\begin{array}{l}7 \\
4\end{array}$ & $\begin{array}{l}\text { Neuropsyphilis in } 2 \\
\text { Meningeal involvement } \\
\text { in } 3\end{array}$ \\
\hline $\begin{array}{l}\text { Investigation of } \\
\text { pyrexia of unknown } \\
\text { origin }\end{array}$ & 4 & $\begin{array}{l}\text { Extracranial tuberculosis } \\
\text { in } 3 \text {; bed sores in } 1\end{array}$ \\
\hline $\begin{array}{l}\text { ? Guillain-Barré } \\
\text { syndrome }\end{array}$ & 3 & $\begin{array}{l}\text { Polymyalgia rheumatica } \\
\text { in } 1 \text {; Wernicke's } \\
\text { encephalopathy in } 1 \text {; } \\
\text { Guillain-Barré in } 1\end{array}$ \\
\hline ? Multiple sclerosis & 2 & $\begin{array}{l}\text { Probable demyelination } \\
\text { in both }\end{array}$ \\
\hline $\begin{array}{l}\text { Follow up of tuber- } \\
\text { culous meningitis }\end{array}$ & 1 & $\begin{array}{l}\text { Infection satis- } \\
\text { factorily treated }\end{array}$ \\
\hline $\begin{array}{l}\text { Known tuberculosis, } \\
\text { ? meningeal } \\
\text { involvement }\end{array}$ & 1 & $\begin{array}{l}\text { No evidence } \\
\text { meningitis }\end{array}$ \\
\hline
\end{tabular}

a depressed level of consciousness did not provide useful discriminatory information.

Papilloedema was recorded as being present in only one patient, who had meningeal involvement with lymphoma. In this case a CT scan was performed before lumbar puncture. CT scans were also recorded as being obtained in two other patients prior to lumbar puncture (one each from Groups 2 and 4) and in 19 patients after lumbar puncture. In four further patients (two from Group 3, one from Group 2 and one with Guillain-Barré syndrome) CT scans were obtained but the relationship to the lumbar puncture was unclear.

There were nine deaths within 24 hours of the lumbar puncture, six in Group 1, two in Group 2, and one in Group 4. In the majority of cases, death was due to progression of the underlying disease but lumbar puncture was almost certainly a contributing factor in some, such as the deeply comatose patient with septicaemia who developed signs of coning progressing to brain stem death. Of the 29 deaths occurring more than 24 hours after lumbar puncture, the majority occurred many days later and only one was probably related to the lumbar puncture. This was a patient with pneumococcal meningitis who had a respiratory arrest at the time of lumbar puncture and progressed to brain stem death 3 days later.

\section{Discussion}

There is little available information on patterns of lumbar puncture usage. The only other study of which I am aware was a survey from the United States which was performed to assess the effect of the introduction of CT scanning on lumbar puncture usage (Marton \& Vender, 1981). The authors also made some observations about the role of lumbar puncture in neurological diagnosis and in particular felt that it was overused in the evaluation of dementia and stroke. However, there were clearly major differences in the populations studied: lumbar puncture was performed on approximately one in every five admissions in the United States survey, a rate ten times that found at Ealing Hospital, making direct comparison difficult.

There was little doubt about the need for lumbaro puncture in the patients listed in Table I. Of the four patients with pyrexia of unknown origin, three were Asian and one was West Indian; tuberculosis was suspected in all and subsequently proven in three.

Although there were no meningeal symptoms or signs, tuberculous meningitis may present very insidiously and lumbar puncture was therefore justified.

The patients presented in Table II were not as straightforward. Indications, when given in the notes, were usually '? meningitis' and/or subarachnoid haemorrhage, but these diagnoses were clearly very unlikely in many of these patients, and lumbar puncture seems to have been used as a screening investigation for undiagnosed neurological disorders.

Table II Final diagnoses and contribution of lumbar puncture to diagnosis in 91 patients. (see text for definition of groups).

\begin{tabular}{|c|c|c|c|c|c|c|c|c|c|c|}
\hline Group & $\mathbf{n}$ & Meningitis & $\begin{array}{l}\text { Vascular } \\
\text { Subarachnoid } \\
\text { haemorrhage }\end{array}$ & $\begin{array}{l}\text { vent } \\
\text { Other }\end{array}$ & $\begin{array}{l}\text { Final diagnos } \\
\text { Underlying } \\
\text { extracranial } \\
\text { infection }\end{array}$ & $\begin{array}{l}\text { Underlying } \\
\text { metabolic } \\
\text { problem }\end{array}$ & Overdose & Other & $\begin{array}{l}\text { No clear } \\
\text { diagnosis }\end{array}$ & $\begin{array}{l}\text { Lumbar puncture } \\
\text { contributing } \\
\text { positively } \\
\text { to diagnosis (\%) }\end{array}$ \\
\hline 1 & 34 & 7 & 5 & 1 & 14 & 3 & - & - & 4 & $12(35)$ \\
\hline 2 & 22 & 2 & 2 & 5 & 2 & 2 & 4 & - & 5 & $4(18)$ \\
\hline 3 & 14 & 1 & - & 2 & - & 6 & - & $3^{*}$ & 2 & $1(7)$ \\
\hline 4 & 21 & - & 4 & 14 & - & 1 & - & $1 \dagger$ & 1 & 4 (19) \\
\hline
\end{tabular}

*1 Hodgkin's disease, 2 dementia

†Thrombotic thrombocytopaenic purpura 
However, lumbar puncture was probably indicated for most of the patients in Group 1 and a number in Groups 2 and 3 (as shown by the detection of three cases of meningitis in these latter two groups). The main relative contra-indication in these groups was a depressed level of consciousness, which may indicate a greater chance of raised intracranial pressure (Duffy, 1969). In those patients that are also pyrexial, however, the risk of a delayed diagnosis of meningitis would favour early lumbar puncture, and indeed of the ten cases of meningitis, seven were both febrile and had a depressed level of consciousness.

The risk/benefit ratio in patients in group 4 is quite different from the other groups. All of these patients, by definition, had focal signs, the majority had a depressed level of consciousness and only a few were pyrexial. The chance that these patients had meningitis was small and in most the final diagnosis was a cerebro-vascular accident. The four patients in this group in whom lumbar puncture contributed to the diagnosis all had a subarachnoid haemorrhage. However, the presence of focal signs and impaired consciousness may be evidence of an intra-cranial haematoma (demonstrated subsequently in two of the four cases), and the risk of coning is then particularly high (Duffy, 1982). Three of these patients had CT

\section{References}

CRAIGMILE, T.K. \& WELCH, K. (1973). Lumbar puncture and analysis of cerebrospinal fluid. In Neurological Surgery, Vol. 1, Youmans, J.R. (ed). pp. 308-324. Sanders: Philadelphia.

DUFFY, G.P. (1969). Lumbar puncture in the presence of raised intracranial pressure. British Medical Journal, 1, 407.

DUFFY, G.P. (1982). Lumbar puncture in spontaneous subarachnoid haemorrhage. British Medical Journal, 285, 1163. would probably have made the diagnosis in the fourth case as well (Findlay, 1980). For the above reasons it has been suggested that CT is the investigation of choice in suspected subarachnoid haemorrhage and that lumbar puncture, if still necessary, should only be performed after CT (Duffy, 1982). However, this position was subsequently challenged (Teddy et al., 1983).

In conclusion, this survey has shown that lumbar puncture is often employed as a screening investigation in neurological illness, as well as for conventional specific indications. This is not inappropriate for most patients presenting with meningeal symptoms or signs and for some patients presenting with disordered consciousness, either acute or subacute in onset. However, the use of lumbar puncture in patients with focal neurological signs is both dangerous and unlikely to yield information unobtainable by other investigations such as CT scanning. Despite the fact that lumbar puncture was commonly used in this latter group, deaths within 24 hours of the lumbar puncture occurred mainly in Group 1 and were usually related to progression of the underlying disease.

\section{Acknowledgement}

I would like to thank the physicians at Ealing Hospital for permission to study the notes of patients under their care.

FINDLAY, G.F.G. (1980). Computer-assisted (axial) tomography in the management of subarachnoid haemorrhage. Surgical Neurology, 13, 125.

MARTON, KI. \& VENDER, M.I. (1981). The lumbar puncture. Patterns of use in clinical practice. Medical Decision Making, 1, 331.

TEDDY, P.J., BRIGGS, M. \& ADAMS, C.B.T. (1983). Lumbar puncture in spontaneous subarachnoid haemorrhage. British Medical Journal, 286, 143. 